\title{
Master's level study: learning transitions towards clinical expertise in physiotherapy
}

\author{
Nicola J. Petty, Julie Scholes, Lorraine Ellis
}

\begin{abstract}
Background Evidence suggests that practitioners who successfully complete a UK Master's level course, accredited by the Manipulation Association of Chartered Physiotherapists (MACP), enhance their clinical practice and demonstrate attributes of clinical expertise. What remains unclear is the process by which practitioners change and enhance their practice. Greater understanding of the learning process would help to inform programme design and delivery, and enhance the quality of the educational experience and impact for practitioners.

Objective To explain the learning process experienced by physiotherapists on completion of an MACP-approved Master of Science (MSc) course.

Design A naturalistic inquiry was conducted using a single theory-seeking case study. Dimensional analysis was used to develop a substantive theory of the learning transition.

Participants Twenty-six semi-structured interviews were carried out with 11 alumni from one MACP-approved MSc programme.

Results The learning transition was from uncritical practice knowledge with routine, therapist-centred clinical practice to critical understanding of practice knowledge that enabled patient-centred practice and the capability to learn in, and from, practice. This development towards clinical expertise was primarily facilitated by critical evaluation of practice knowledge, particularly through mentorship in clinical practice. This highly challenging experience was helped by high levels of support from the mentor. The learning transition varied between participants and depended on a host of moderating factors.

Conclusion This is the first documented theoretical explanation of how physiotherapists enhance their clinical practice and develop attributes of clinical expertise within an MACP-approved MSc course. This explanatory theory may be of value for educational programmes that seek to facilitate practitioners' development towards clinical expertise. This study also offers a novel model of learning transition that may be applicable to other educational settings.
\end{abstract}

Keywords: Learning transitions; MSc; Physiotherapist; Clinical expertise

\section{Introduction}

In the UK, there are currently 11 Master's level courses approved by the Manipulation Association of Chartered Physiotherapists (MACP). These courses follow the educational standards of the International Federation of Orthopaedic Manipulative Physical Therapists with a minimum of 200 hours of neuromusculoskeletal physiotherapy theory, 150 hours of practical skill development and 150 hours of mentored clinical practice. A major focus of these courses is to develop clinical expertise and enable successful practitioners to obtain advanced clinical practice and extended-scope practitioner roles [1].

Two qualitative studies have explored the impact of an MACP-approved Master of Science (MSc) degree on practitioners [2,3]. A phenomenological study [3] using focus group interviews found that practitioners changed their practice in ways that suggested enhanced clinical expertise. They 
adopted a patient-centred approach, a holistic view of problematic clinical situations, had broader options in clinical decision-making, gave more attention to educate and coach patients, and learnt how to learn. In the other study [2], postal questionnaires were used to explore the career development and roles of 48 alumni from an MACP-approved MSc course. Participants gained enhanced clinical and manual skills, a greater depth of knowledge, improved clinical reasoning, and an ability to evaluate research and apply evidence-based practice. Similar findings have been reported following a year-long advanced manual therapy course in the USA [4], as well as from UK Master's level study by occupational therapists [5] and nurses [6]. While these studies suggest that practitioners enhanced their practice, there is no unifying conceptual or explanatory framework for this change. Understanding how practitioners learn and develop is important if educational programmes are to efficiently and effectively facilitate practitioners' development towards clinical expertise.

The conceptual framework of learning transition theory coined by Scholes [7] informed the focus of this study. The term 'learning transition' is used here to refer to the process of change (in attitude, knowledge and behaviour) of a practitioner as a consequence of a learning experience. It has its roots within role transition theory [8] with which it shares key terms. Learning transition follows a number of stages: antecedent conditions, expectations of the learning experience, learning contradiction that triggers learning, the reaction of the individual to this contradiction, and learning outcomes. Moderating factors are the personal characteristics of the practitioner that influence each stage. Antecedent conditions identify particular factors present at enrolment that influence expectations of learning. While expectations that are met may lead to increased confidence, this does not create the cognitive dissonance necessary for learning $[9,10]$. Fundamental to learning transition theory is the need for new knowledge and experience to contradict previously held knowledge and experience [7,11-13], and is often associated with strong emotional reactions [7,14-18]. The learning outcome of contradiction triggers change in practitioners' knowledge, attitude and behaviour, as they re-interpret past assumptions and experiences [7], and modify personal theories [19-21]. A variety of moderating factors influence and help to explain why individuals experience quite different learning transitions $[7,8]$. The aim of this study was to develop an explanatory theory of the learning transition of neuromusculoskeletal physiotherapists on completion of an MACP-approved MSc programme.

\section{Methods}

\section{Study design}

A naturalistic inquiry [22,23] using a single theoryseeking case study design [24,25] was used. Through
Table 1

Profile of participants $(n=11)$.

\begin{tabular}{ll}
\hline $\begin{array}{l}\text { Mean age } \\
\text { Mean years in clinical } \\
\text { practice at the start of the } \\
\text { study }\end{array}$ & 38.2 (range 31 to 52) \\
Practice setting & 8.5 (range 3 to 24) \\
& \\
& 4 in private practice \\
& 7 in NHS: 1 at Band 7,4 at \\
Mean years since completed & Band 8A and 2 at Band $8 \mathrm{~b}$ \\
MACP-approved MSc & 2.4 (range 2 months to 5 \\
\hline
\end{tabular}

NHS, National Health Service; MACP, Manipulation Association of Chartered Physiotherapists; MSc, Master of Science.

description of an individual's learning experience, shared understanding and meaning were co-constructed by the participants and the researcher (NJP).

\section{Participants}

Thirty-five alumni who had successfully completed the MSc Neuromusculoskeletal Physiotherapy course at one UK university were identified from the open access pages of the MACP website (http://www.macpweb.org). Purposeful sampling was used to ensure a wide range of experiences and perceptions from across cohort years, graduation years, work settings and gender. Eleven alumni agreed to participate and gave informed consent; their biographical information is given in Table 1. Approval for the study was obtained from the University of Brighton Research Ethics and Governance Committee.

\section{Data collection and analysis}

Data collection and analysis followed an iterative process and was carried out by the researcher, who was course leader and module leader of MACP-specific modules when participants had undertaken the MSc course. This prior knowledge over a 10-year span was considered data in the form of observational memory and helped to inform data analysis.

The study sought to explore the learning experience perceived by alumni after completion of the course, and for that reason, the primary data were collected through individual interviews. A total of 28 audio-recorded, semi-structured interviews (amounting to 19 hours) were conducted face to face or via the telephone between January 2005 and April 2007. All but one of the participants was interviewed two or three times. Each interview was transcribed by the researcher and sent to the participant to check for accuracy. Once agreed, the transcription became research data. The first round of interviews explored their experience completing the MSc course and its influence on their clinical practice. Data analysis was facilitated by role transition theory [8]. Mapping the data to this conceptual framework identified further questions and led to the second round of interviews. The literature on learning transition theory [7] and social learning theory 
$[26,27]$ guided further analysis and led to the third and final round of interviews.

The transcriptions were read and reread to allow familiarisation with the data. Dimensional analysis [28,29] was used and involved three inter-related stages. The first expanded the data into various attributes designated as dimensions with associated properties; this aimed to identify 'what all is involved here' [29, p. 310]. Differentiation then determined the salience and relationship of dimensions to each other to create an explanatory matrix [30]. Finally, integration involved writing a theoretical account of the matrix, which prompted further analysis and its adaptation into a coherent substantive theory.

\section{Trustworthiness}

Insider research requires strategies to minimise researcher and participant bias that would otherwise threaten the trustworthiness of the study [31]. The researcher offset bias by taking a reflexive and critically reflective stance throughout the 3 years of data collection and analysis. The extended period of time allowed development of a strong researcher identity with disengagement from the roles of course and module leader. Bias was also offset by frequent verification checks of the analysis by participants. Participant bias was offset by a respectful and trusting researcher-participant relationship that developed and became established over a prolonged period of time (1-2 years).

\section{Results}

The theoretical explanation of the learning transition experienced by participants is portrayed in Fig. 1 and involves a developmental process indicated by arrowheads from left to right; each of these stages will be explored in turn, supported by illustrative extracts. Participants are identified as P1, P2, etc. A variety of moderating factors help to explain differences in the learning transition experienced by participants (Table 2). How these factors appeared to influence all stages of the learning transition is discussed below, in particular how participants managed their reaction to the learning contradiction. To enhance clarity of the theory, the model demonstrates polar extremes; however, it is more likely that participants were somewhere along the continuum. A more detailed review of the findings can be found elsewhere [32].

\section{Antecedent conditions}

Participants had not shared and critically explored their theoretical knowledge and clinical practice with colleagues prior to enrolment on the MSc course. While they may have occasionally discussed patients with colleagues, they did not generally observe each other with patients and their practice was 'hidden' behind screened cubicles. In addition, participants tended to regard knowledge as right or wrong, and uncritically accepted knowledge from those in authority; that is, they had 'received practice knowledge' [33]. This view of certain, unproblematic knowledge was then applied in practice to solve simple predictable clinical problems. 'Practice knowledge' is used here as an umbrella term to refer to all types of knowledge (propositional, practical, tacit, etc.) and processing of knowledge (cognition, metacognition, clinical reasoning) by a practitioner in clinical practice [34-38].

Clinical practice was characterised as routine and therapist centred. Participants used habitual, repetitive ways, with minimal deliberation, to examine, treat and manage people with neuromusculoskeletal conditions, rather than adapting and fine tuning to each individual. These findings were deduced from enhanced criticality gained through completion of the MSc course. A typical comment from participants was:

'I'd do the subjective [examination] and ask the patient routine questions. I'd not really take information from my subjective into the objective. I'd do a routine objective examination.' (P4)

\section{Expectations}

Participants expected to enhance their knowledge and skills progressively through didactic teaching from a skilled and informed tutor. They expected to be given information and be told how to perform skills:

'One thing I was surprised with was that I thought the teaching would be more prescriptive, I thought when I was being taught, I would be told do like this, this and this and somebody would come in and tell me how to do it. But it wasn't actually like that; it was quite student led with lots of discussions.' (P7)

'The practical hands-on skill were taught differently than I was used to and the way I expected. On the weekend clinical courses, there was a way to do something. On the MSc, techniques were taught more openly, less prescriptive, which was liberating really.' (P3)

\section{Learning contradiction}

The contradiction that triggered learning involved critical evaluation of their practice knowledge. This was particularly pertinent within musculoskeletal-specific modules that involved 6 weeks of classroom-based teaching and 6 weeks of clinical practice. Some aspects of practice knowledge were more challenging than others. Giving and receiving critical feedback on their handling skills posed relatively little challenge; they were familiar with this during in-service training and weekend courses. Critical classroom discussion that explored theoretical knowledge and reasoning was less familiar and posed a greater challenge. By far the greatest challenge and most powerful learning experience was an MACP mentor directly observing their clinical practice with patients, and providing critical evaluation and feedback of their per- 


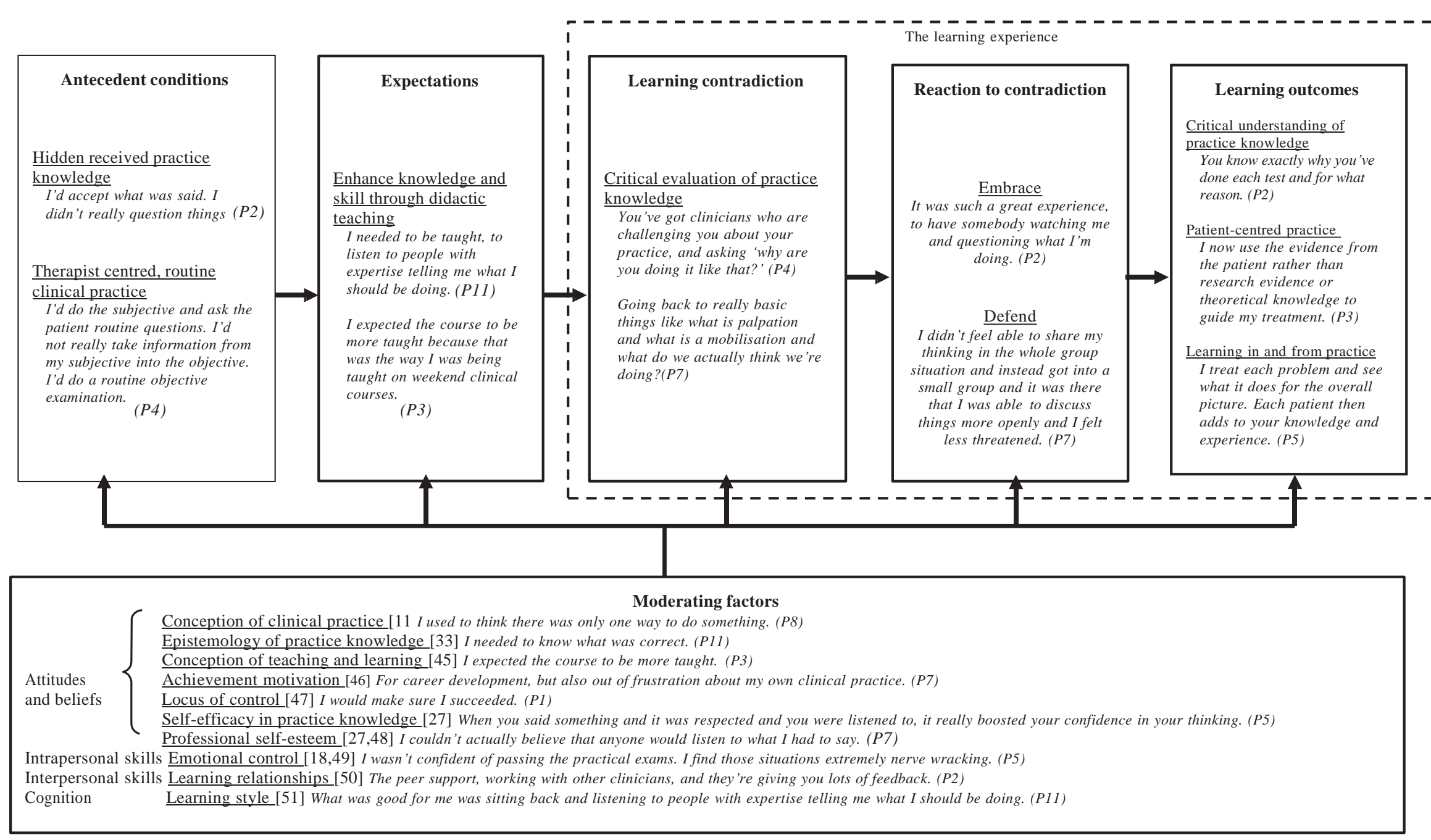

Fig. 1. Explanatory theory of the learning transitions experienced by physiotherapists on completion of a Master of Science degree. The antecedent conditions provide the precourse contextual factors relevant to the learning experience. Expectations of the learning experience influenced the perception of the experience. The learning experience incorporates the learning contradiction that triggered learning, the subsequent reaction of the practitioner and the learning outcomes. Moderating factors are the personal characteristics of the practitioner that influenced the process. 

Table 2

Moderating factors and properties that influenced whether participants were receptive or defensive towards critical evaluation of their practice knowledge.

\begin{tabular}{|c|c|c|c|}
\hline Moderating factors & & Receptive & Defensive \\
\hline \multirow[t]{7}{*}{ Attitudes and beliefs } & $\begin{array}{l}\text { Conception of clinical } \\
\text { practice }\end{array}$ & $\begin{array}{l}\text { Professional artistry: consider practice } \\
\text { knowledge as temporary, dynamic and } \\
\text { problematic; seek critical evaluation to aid } \\
\text { understanding }\end{array}$ & $\begin{array}{l}\text { Technical rationality: consider practice } \\
\text { knowledge concrete, permanent and } \\
\text { unproblematic; critical evaluation not necessary }\end{array}$ \\
\hline & $\begin{array}{l}\text { Epistemology of practice } \\
\text { knowledge }\end{array}$ & $\begin{array}{l}\text { Relativist, constructed knowledge: may seek } \\
\text { critical discussion with peers and tutors }\end{array}$ & $\begin{array}{l}\text { Received knowledge: may seek 'right' answers } \\
\text { from those in authority }\end{array}$ \\
\hline & $\begin{array}{l}\text { Conception of teaching and } \\
\text { learning }\end{array}$ & $\begin{array}{l}\text { Student-centred facilitation of learning: seek to } \\
\text { learn from others (peers and tutors) }\end{array}$ & $\begin{array}{l}\text { Didactic transmission of knowledge: seek to } \\
\text { learn from tutor }\end{array}$ \\
\hline & Achievement motivation & Learning goals: focused on learning & $\begin{array}{l}\text { Performance goals: focused on formal } \\
\text { assessments and expectations of tutor to ensure } \\
\text { success }\end{array}$ \\
\hline & Locus of control & $\begin{array}{l}\text { Internal: proactive in their learning, looked } \\
\text { within themselves }\end{array}$ & $\begin{array}{l}\text { External: passive learners and may have adopted } \\
\text { a learned helplessness }\end{array}$ \\
\hline & $\begin{array}{l}\text { Perceived self-efficacy in } \\
\text { practice knowledge }\end{array}$ & $\begin{array}{l}\text { Realistic estimation: aware of need to learn and } \\
\text { engage with others }\end{array}$ & $\begin{array}{l}\text { Underestimation: reluctant to participate, } \\
\text { believing they had little to offer others } \\
\text { Overestimation: unaware of a need to enhance } \\
\text { and develop their knowledge and reluctant to } \\
\text { listen to others to hear alternative views }\end{array}$ \\
\hline & $\begin{array}{l}\text { Professional self-esteem as a } \\
\text { physiotherapist }\end{array}$ & $\begin{array}{l}\text { Realistic estimation: self-awareness and } \\
\text { appreciation of others to help facilitate learning }\end{array}$ & $\begin{array}{l}\text { Underestimation: sense of inadequacy to offer a } \\
\text { valuable contribution to others and thus a } \\
\text { reluctance to engage } \\
\text { Overestimation: self-sufficiency and reluctant to } \\
\text { listen and learn from others }\end{array}$ \\
\hline Intrapersonal skills & Emotional control & $\begin{array}{l}\text { Learning satisfaction and pleasure: able to } \\
\text { participate and engage }\end{array}$ & $\begin{array}{l}\text { Learning anxiety and stress: reluctant to } \\
\text { participate and engage }\end{array}$ \\
\hline Interpersonal skills & Learning relationships & $\begin{array}{l}\text { Adult stance: safe, supportive and constructive } \\
\text { learning relationships with student peers and } \\
\text { tutors }\end{array}$ & $\begin{array}{l}\text { Child or parent stance: unsupportive and } \\
\text { destructive relationships with student peers and } \\
\text { tutors }\end{array}$ \\
\hline Cognition & Learning styles preference & $\begin{array}{l}\text { Reflective observation and abstract } \\
\text { conceptualisation: comfortable with critical } \\
\text { discussions that trigger thinking and reflection }\end{array}$ & $\begin{array}{l}\text { Active experimentation with concrete } \\
\text { experience: impatient with critical discussions, } \\
\text { preferring action-orientated activities such as } \\
\text { practical hands-on skills }\end{array}$ \\
\hline
\end{tabular}

formance. They had not experienced this since qualifying as a physiotherapist:

'I found the placements really, really helpful and even though it was very, very difficult, it was probably the most positive thing to come out of the course. In my practice, I'm still using aspects of the clinical reasoning and the key criteria that I learnt on placement and use it in my undergraduate and postgraduate teaching.' (P7)

'I could see that within 1 week, my practice was already changing and improving. Within 3 weeks, my practice had completely altered, it was such a fantastic experience.' (P10)

\section{Reaction to the contradiction}

The reaction of participants to critical evaluation of their practice knowledge lay along a continuum from defending against to being receptive of the experience. Defensive behaviours involved avoidance of classroom discussion and peer learning, and a preference for receiving knowledge from tutors. A defensive position tended to be associated with anxiety and stress, while those who embraced the new experience and opportunity it afforded felt pleasure and satisfaction.
Direct observation and feedback by a MACP mentor while on clinical placement severely limited defence against critical evaluation of their practice. Some participants felt 'terrified' and 'scared to death' at the prospect of such close scrutiny of their practice, but their fears were quickly allayed as they received constructive feedback and support from the mentor. Letting go of past thinking and habits, gaining new knowledge and skills, and receiving positive feedback were associated with optimistic feelings of pleasure and satisfaction described as 'enjoyable' (P7), 'interesting' (P3), 'great' (P2) and 'fantastic' (P10, 11). For a few participants, however, the placement was 'painful' (P1) and 'traumatic' (P8) as they became aware of gaps and errors, received negative feedback, and tried out new ways to think and practice. The 'high intellectual interference' [7, p. 148] and high challenge associated with the placement required high levels of support from the mentor; where this was not forthcoming, strong negative emotions were experienced. The more participants genuinely engaged in critical evaluation of their practice knowledge, the more they experienced a radical and powerful transformation of their practice knowledge and clinical practice. Explicating practice knowledge enabled it to become less personally embedded [39], liberating and empowering [40] participants to seek contradiction: 


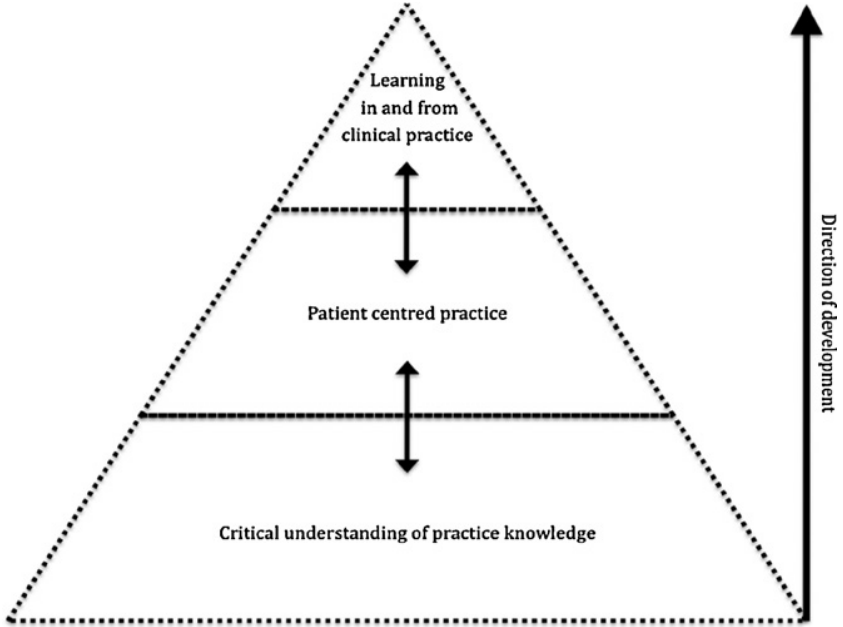

Fig. 2. Learning outcomes: critical understanding was the initial change that led to patient-centred practice which then led to a capability to learn in, and from, practice.

'We'd listen to each other and when you said something and it was respected and you were listened to, it really boosted your confidence in your thinking and in your opinions.' (P5)

'With my first patient, I was watched and I thought 'oh no, what are they going to think about me', but that feeling very quickly disappeared. . .I thought 'I'm here to learn, I'm here to get something out of this placement, and therefore I want them to look at what I'm doing and say, 'don't do it like that, perhaps do it like this'... Within 3 weeks, my practice had completely altered, it was such a fantastic experience. In the final week and a half, I was asking my educator to come and watch me. . . and give me their input and feedback.' (P10)

\section{Learning outcomes}

Three inter-related learning outcomes are depicted in Fig. 2. Critical understanding was the initial change that enabled practitioners to become patient centred, and this led to capability to learn in, and from, their clinical practice.

\section{Critical understanding of practice knowledge}

'I've improved my thought processes behind what I'm doing and why I'm doing it; my ability to reflect, my ability to deduce what information that test has given me and the value of that information in terms of the evidence base.' (P10)

'I can move logically, but still quite creatively, and can justify what I am actually doing and have some logic to my treatment.' (P7)

Participants gained an enhanced understanding of the subjective and physical examination process, and how to make sense and assess the findings from an individual patient examination. They were better able to choose and apply appropriate treatment and management strategies for their patients, and considered they were more efficient and effective clinicians. They became more critically evaluative of their practice knowledge and that of others, and were better able to justify their clinical decisions to themselves, their patients and other health professionals.

Critical evaluation of taken-for-granted assumptions, beliefs, values, expectations, perceptions, judgements and actions may generate new perspectives, actions and meanings [41]. With continued critical evaluation, these may then become more discriminating, integrated, differentiated, open [42], dependable and justified [43], leading to more complex and comprehensive embodied understanding $[20,44]$. Engagement in the process of critical evaluation may also foster a tentative, experimental and sceptical attitude towards practice knowledge [19]. Thus, critical evaluation may enhance both understanding of, and criticality towards, practice knowledge.

\section{Patient-centred practice}

Participants adapted their examination, treatment and management strategies to the individual patient, becoming more deliberate and creative. This enhanced their ability to manage people with more complex presentations. They used information from the patient to guide their management. They were critically reflective of their practice, habitually evaluating the effectiveness of their decisions through patient re-assessment.

\section{Capability to learn in and from clinical practice}

A critically reflective stance towards their clinical practice led to habitual cycles of assessment-re-assessment to guide patient management. This enabled them to evaluate the effectiveness of their clinical decisions and learn from their patients; in this way, they were able to learn in, and from, their clinical practice:

'You have the basics and you have the patients and then you've got to learn from that. . .just reflecting on why things worked or didn't.' (P6)

'I treat each problem and see what it does for the overall picture. Each patient then adds to your knowledge and experience so you become more efficient.' (P5)

\section{Limitations of the study}

Limitations of this study have already been explored within the section on trustworthiness. This single case study was conducted in one UK university. The learning transition described here provides a 'fuzzy' [24] generalisation of what may happen in other situations; the findings may be transferable elsewhere. The reader is reminded that the theory has been constructed by the researcher from data co-created with the participants, and as such is caught in time and place. Further research is needed to test the theory in other educational settings. 


\section{Conclusion}

This study offers the first documented theoretical explanation of the learning transition of practitioners within a MACP-approved MSc course. The key trigger to their learning and development towards clinical expertise was the learning contradiction of critically evaluating their practice knowledge, and this was most significant in clinical practice with an MACP mentor.

The key findings from this study are that, prior to enrolment on to the MSc course, participants had hidden received practice knowledge and engaged in therapist-centred practice. The course involved critical evaluation of practice knowledge, which was particularly challenging in clinical practice with an MACP mentor. This highly challenging experience was helped by high levels of support from the mentor. The reaction of participants to this contradictory learning experience was influenced by a number of moderating factors that affected the learning outcomes. Participants gained, to varying degrees, critical understanding of practice knowledge, patient-centred practice and capability to learn in, and from, practice. This explanatory theory offers understanding of how practitioners learnt and developed which may be of value for educational programmes that seek to facilitate practitioners' development towards clinical expertise. This study also offers a novel model of learning transition that may be applicable to other educational settings.

\section{Acknowledgements}

The authors wish to thank the participants who took part in this study, and Dr Vinette Cross for critically commenting on the manuscript.

Ethical approval: University of Brighton Research Ethics Committee Minute 248.2 REC05-30.

\section{References}

[1] Chartered Society of Physiotherapy. Chartered physiotherapists working as extended scope practitioners (ESP). Information paper PA29. London: Chartered Society of Physiotherapy; 2002.

[2] Green A, Perry J, Harrison K. The influence of a postgraduate clinical master's qualification in manual therapy on the careers of physiotherapists in the United Kingdom. Man Ther 2007;13:139-47.

[3] Stathopoulos I, Harrison K. Study at master's level by practising physiotherapists. Physiotherapy 2003;89:158-69.

[4] Smith KL, Tichenor CJ, Schroeder M. Orthopaedic residency training: a survey of the graduates' perspective. J Orthop Sports Phys Ther 1999;29:635-55.

[5] Conneeley AL. Study at master's level: a qualitative study exploring the experience of students. Br J Occup Ther 2005;68:104-9.

[6] Whyte DA, Lugton J, Fawcett TN. Fit for purpose: the relevance of master's preparation for the professional practice of nursing: a followup study of postgraduate nursing courses in the University of Edinburgh. J Adv Nurs 2000;31:1072-80.
[7] Scholes J. Developing expertise in critical care nursing. Oxford: Blackwell; 2006.

[8] Allen VL, van de Vliert E. Role transitions, explorations and explanations. New York: Plenum; 1984.

[9] Dewey J. Experience and education. New York: Touchstone; 1938/1997.

[10] Eraut M, Editorial. The many meanings of theory and practice. Learn Health Soc Care 2003;2:61-5.

[11] Fish D, Coles C. Developing professional judgement in health care. Oxford: Butterworth-Heinemann; 1998.

[12] Jarvis P. The practitioner-researcher. Developing theory from practice. San Francisco: Jossey-Bass; 1999.

[13] Rolfe G. Beyond expertise: reflective and reflexive nursing practice. In: Johns C, Freshwater D, editors. Transforming nursing through reflective practice. Oxford: Blackwell Science; 1998. p. 21-31.

[14] Dirkx JM. Engaging emotions in adult learning: a Jungian perspective on emotion and transformative learning. New Direct Adult Contin Educ 2006;109:15-26.

[15] Eraut M, Editorial. Learning to change and/or changing to learn. Learn Health Soc Care 2004;3:111-7.

[16] Eraut M, Feedback. Learn Health Soc. Care 2006;5:111-8.

[17] Griffiths D. Stress. In: Griffiths D, editor. Psychology and medicine. London: British Psychological Society and Macmillan; 1981. p. 296-322.

[18] Hopson B. Transition: understanding and managing personal change. In: Griffiths D, editor. Psychology and medicine. London: British Psychological Society and Macmillan; 1981. p. 323-48.

[19] Argyris C, Schon DA. Theory in practice, increasing professional effectiveness. San Francisco: Jossey-Bass; 1974.

[20] Dall'Alba G, Sandberg J. Unveiling professional development: a critical review of stage models. Rev Educ Res 2006;76:383-412.

[21] Schon DA. The reflective practitioner, how professionals think in action. Aldershot: Ashgate Arena; 1991.

[22] Erlandson DA, Harris EL, Skipper BL, Allen SD. Doing naturalistic inquiry, a guide to methods. Newbury Park: Sage; 1993.

[23] Guba EG, Lincoln YS. Effective evaluation: improving the usefulness of evaluation results through responsive and naturalistic approaches. San Francisco: Jossey-Bass; 1981.

[24] Bassey M. Case study research in educational settings. Maidenhead: Open University; 1999.

[25] Simons H. Case study research in practice. Los Angeles: Sage; 2009.

[26] Bandura A. Social learning theory. Englewood Cliffs: Prentice-Hall; 1977.

[27] Bandura A. Self perceived self efficacy, the exercise of control. New York: WH Freeman and Co; 1997.

[28] Bowers B, Schatzman L. Dimensional analysis. In: Morse JM, Stern PN, Corbin J, Bowers B, Charmaz K, Clarke AE, et al., editors. Developing grounded theory, the second generation. Walnut Creek California: Left Coast; 2007. p. 86-126.

[29] Schatzman L. Dimensional analysis: notes on an alternative approach to the grounding of theory in qualitative research. In: Maines DR, editor. Social organisation and social process. New York: Aldine De Gruyter; 1991. p. 303-14.

[30] Kools S, McCarthy M, Durham R, Robrecht L. Dimensional analysis: broadening the conception of grounded theory. Qualitat Health Res 1996;6:312-30.

[31] Mercer J. The challenges of insider research in educational institutions: wielding a double-edged sword and resolving delicate dilemmas. Oxf Rev Educ 2007;33:1-17.

[32] Petty NJ. Towards clinical expertise: learning transitions of neuromusculoskeletal physiotherapists. Unpublished; 2009.

[33] Belenky MF, Clinchy BM, Goldberger NR, Tarule JM. Women's ways of knowing. 10th ed. New York: Basicbooks; 1986.

[34] Higgs J, Jones M. Clinical reasoning in the health professions. 2nd ed. Oxford: Butterworth-Heinemann; 2000.

[35] Higgs J, Richardson B, Dahlgren MA. Developing practice knowledge for health professionals. Edinburgh: Butterworth-Heinemann; 2004. 
[36] Higgs J, Titchen A. Knowledge and reasoning. In: Higgs J, Jones M, editors. Clinical reasoning in the health professions. 2nd ed. Oxford: Butterworth Heinemann; 2000. p. 23-32.

[37] Jensen GM, Gwyer J, Hack LM, Shepard KF. Expertise in physical therapy practice. Boston: Butterworth Heinemann; 1999.

[38] Eraut M. Developing professional knowledge and competence. London: RoutledgeFalmer; 1994.

[39] Kegan R. What "form" transforms? A constructive-developmental approach to transformative learning. In: Mezirow J, editor. Learning as transformation, critical perspectives on a theory in progress. San Francisco: Jossey-Bass; 2000. p. 35-69.

[40] Mezirow J. Learning as transformation, critical perspectives on a theory in progress. San Francisco: Jossey-Bass; 2000.

[41] Titchen A. Critical companionship: a conceptual framework for developing expertise. In: Higgs J, Titchen A, editors. Practice knowledge and expertise in the health professions. Oxford: Butterworth Heinemann; 2001. p. 80-90.

[42] Mezirow J. Transformative dimensions of adult learning. California San Francisco: Jossey-Bass; 1991.

[43] Cranton P. Individual differences and transformative learning. In: Mezirow J, editor. Learning as transformation, critical perspectives on a theory in progress. California: Jossey-Bass; 2000. p. 181204.

[44] Dall'Alba G. Understanding professional practice: investigations before and after an educational programme. Stud High Educ 2004;29:679-92.

[45] Ng KC, Murphy D, Jenkins W. The teacher's role in supporting a learner-centred learning environment: voices from a group of parttime postgraduate students in Hong Kong. Int $\mathrm{J}$ Lifelong Learn 2002;21:462-73.

[46] Dweck CS. Self-theories: their role in motivation, personality and development. Replace Philadelphia with 'Hove' Philadelphia: Psychology Press; 2000.

[47] Weiner B. Achievement motivation and attribution theory. Morristown: General Learning; 1974.

[48] Fennell M. Overcoming low self-esteem. A self-help guide using cognitive behavioural techniques. London: Robinson; 1999.

[49] Goleman D. Emotional intelligence. London: Bloomsbury; 1996.

[50] Harris TA. I'm ok-you're ok. London: Pan Books; 1973.

[51] Kolb DA. Experiential learning. Englewood Cliffs: Prentice-Hall; 1984. 